This item was submitted to Loughborough's Institutional Repository (https://dspace.lboro.ac.uk/) by the author and is made available under the following Creative Commons Licence conditions.

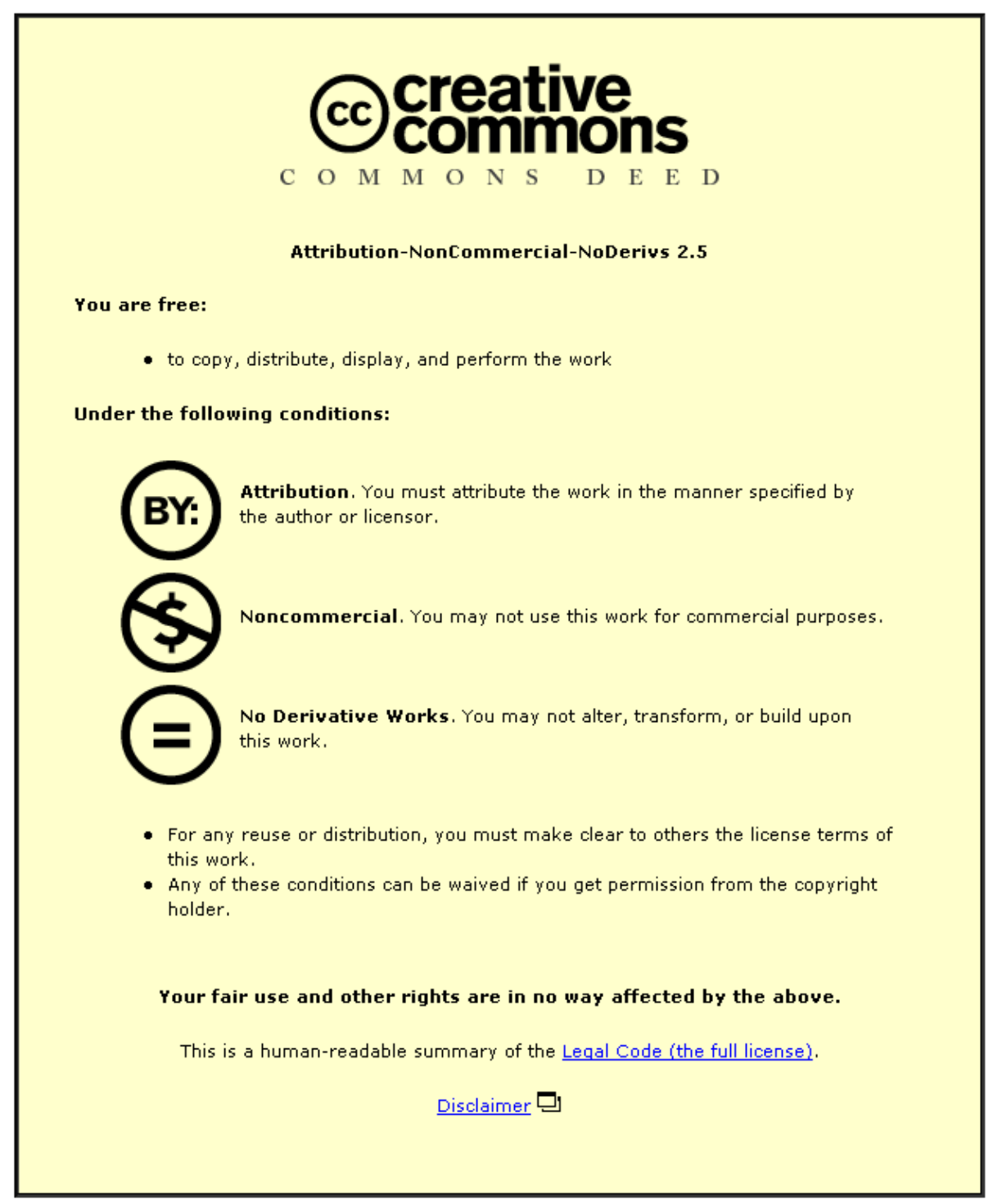

For the full text of this licence, please go to: http://creativecommons.org/licenses/by-nc-nd/2.5/ 


\title{
Critical success factors in collaborative multi-disciplinary design projects
}

\author{
Koutsikouri, D, Austin, SA and Dainty, ARJ \\ Journal of Engineering, Design and Technology, Vol.6, No.3, pp 198-226
}

Purpose - The purpose of this paper is to explore critical success factors (CSFs) in interdisciplinary building design projects from the view point of the project members themselves. While there is a plethora of research on CSFs, there is a paucity of studies that examine CSFs within this unique project context.

Design/methodology/approach - Semi-structured interviews, a survey and facilitated workshops were used to identify factors and their interrelationships within the project context. Findings -Thirty one primary CSFs were distilled which were then further grouped into four interdependent group factors: management factors, design team factors, competencies and resources factors and project enablers. It would appear that there are factors that are particularly important in such project environments, which do not figure strongly in other project environments. These factors are related to the socio-political dynamics of inter-disciplinary team work such as passion and enthusiasm, shared values, creativity and innovation and represent so called 'super soft factors' which reflect personal success and its importance in achieving positive project outcomes.

Research limitations/implications - Although there has been significant research on critical success factors (CSF) in construction projects, little attention has been paid to those which are related to the collaborative design phase of such projects.

Practical implications - The results suggest that it is worthwhile for managers in construction related organisations and beyond to recognise the interdependencies which exist between the project context, processes and the project members' experience and affinity to the project and the team itself in project work to achieve desired outcomes.

Originality/value - This paper extends the CSF literature by identifying the nature of the primary factors and their interrelationships which influence project outcomes in collaborative design projects.

Key words: Construction management; Critical success factors; Interdisciplinary design; Project success.

Article type: Case study

\section{INTRODUCTION}

The study of critical success factors has contributed to a more comprehensive understanding of project success and failure across many industry sectors. According to Morris (2006) this research has broadened the scope of project management and what knowledge is needed to manage projects more effectively (see, e.g. APM BOK, 2005). In generic terms, this knowledge and associated information flow is essential to assist managers in directing their organisation to successful long-term existence and growth. Despite the abundance of tools and techniques to support the management of projects however, managers still struggle to deliver them successfully. In the architecture-engineering-construction (AEC) industry where projects depend on collaborative working between a variety of stakeholders the difficulty has been attributed to lack of time and ability to develop and maintain a team approach to the management of projects (Bresnen, 1990). It has been argued that mainstream project management methods and techniques are not enough to guarantee improved performance in such multi-organisational settings (Thomas, 2006). Such claims reinforce the need for a more comprehensive and contextually embedded understanding of the pattern of success factors which underpin positive 
project outcomes and overall success (Cooke-Davies, 2001; Morris et al., 2004). Thus, a more holistic understanding of how to manage complex projects is required which is grounded in research insights drawn from real world settings. It is against this background that the research began with the case study organisation, a multi-disciplinary design engineering consultancy. The impetus for this research stems from a genuine interest to gain a better understanding of the drivers of project success as well as discovering real insights into collaborative working. The study explored CSFs inter-disciplinary design projects from the perspective of the project team members in order to establish perceptions of what it takes to achieve positive project outcomes in such collaborative endeavours. More importantly, the factors are mapped onto a generic systems model to reveal interrelationships between technical, human and organisational factors. There is a paucity of guidance for managing success in design projects which go beyond the global key performance indicators (KPIs) developed for the construction industry (see Egan, 1998; Latham, 1994; and Chan et al., 2004). In addition, previous studies on CSFs only have provided a limited insight into the unique project environments of building design. This research aims to bridge this gap by providing an initial template of context specific variables which are particularly important for managing inter-disciplinary design projects. In other words, the findings may influence the way inter-disciplinary work is conceptualised and managed in the future to stand a better chance of success, by providing a holistic view of the factors that are crucial to improve collaborative endeavours.

\section{Critical success factors in project-based environments}

Determining critical success factors (CSFs) is an established method for organisational analysis. The approach was first proposed by Rockart (1979) who defined it as a means of identifying the essential elements that need to be addressed for organisations to implement change more effectively. Within a project context, CSFs can be described as the factors that the manager needs to keep a firm eye on to achieve a successful delivery. The implication is that if critical success factors are not present or taken into consideration, problems will be experienced which may act as barriers to success (cf Andersen et al., 2006). Numerous studies have been conducted to identify these 'critical' factors, especially within information systems, R\&D and various engineering environments.

There are several success models and frameworks available, but they are not particularly consistent in terms of classifying success factors, which reflects that context matters in understanding drivers of success. As noted by Jugdev and Müller (2005): 'project success is ambiguous and highly context dependent'. Consequently, what is considered to lead to success is coloured by personal perception and by the circumstances under which the judgement is made. Nonetheless, despite the ambiguities surrounding the term, the topic of CSFs continues to attract interest from the academic and professional communities.

According to Cooke-Davies (2002), a comprehensive answer to the question of which factors are critical depends on answering three separate questions: What factors lead to project management success?; What factors lead to a successful project?; and What factors lead to consistently successful projects? He also makes two major distinctions based on empirical findings. Firstly, he distinguishes between project success (measured against the overall objectives of the project), and project management success (measured against traditional measures of performance such as cost, time and quality). Secondly, he distinguishes between success criteria (the measures by which success or failure of a project will be judged) and success factors (those inputs to the management system that lead directly to the success of the project). Because of this definitional complexity, it has been difficult to develop an appropriate way to measure 'success' as an holistic entity.

A recent review of the CSF literature (Fortune and White, 2006) demonstrates clearly that there is lack of consensus between authors and researchers regarding what factors affect project success. They found that the three most cited factors are: the importance of a project receiving support from senior management; having clear and realistic objectives; and producing an efficient plan. However, although $81 \%$ of the publications include at least one of these three 
factors, only 17 out of 63 cite all three. Perhaps their most interesting finding is that there is a lot of overlap between sets of CSFs but the factors selected for inclusion in individual lists vary to a considerable extent. Further, they highlight the main reservation that have been expressed about the CSFs approach; 'that the inter-relationships between factors are at least as important as the individual factors but the CSFs approach does not provide a mechanism for taking account of these inter-relationships (p. 54). Accordingly, a model, the Formal Systems Model (FSM) (see Fortune and Bignall, 1984) were used as a framing device to deliver the benefits of taking into account of the CSFs that were culled in the literature review whilst overcoming problems associated with their use. In other words, their research shows that it is possible to map most CSFs with the features of the FSM model. The model is featured in Figure 2.

Overall this stresses the importance of creating an environment in which projects can succeed (Newell et al., 2002; Pinto et al., 2004) rather than focusing on the success of single projects. It also brings attention to the strategic importance of linking project management effort to long-term organisational effectiveness. Additionally, although most studies emphasise different success factors, there seem to be relative consensus on the importance of human factors or 'people' for successful project outcomes (Lechler, 2000). The 'discovery' that performance and success is achieved through people draws attention to the role of individuals and their relationships in the project process. This implies that the management of people; ie the ability to influence, encourage and motivate individuals and teams, is becoming a necessary skill among the twenty first century project mangers (Pryke and Smyth, 2006).

In light of this, a diversified and much more holistic understanding of project success is necessary, particularly in settings where practitioners must manage multiple projects at various stages of their life cycles and face competing priorities on a daily basis (Jugdev et al., 2005; Morris, 2006; Cicmil and Hodgson, 2006). As a response to this a number of authors have argued that project success and failure can be best understood and dealt with through the use of systems thinking (eg., Bignell et al., 1984; Morris and Hough, 1987; Fortune and Peters, 2005). This line of research places the spotlight on the connection of 'hard' (e.g. cost, time and to specification; physical resources) and 'soft' (e.g. multiple perspectives, communication, emotional intelligence) factors and the wider managerial and social frameworks within which individuals work in making sense of project outcomes.

\section{Critical success factors in construction projects}

In recent years, researchers in construction and construction project management have become increasingly interested in critical success/failure factors (eg. Ashley et al., 1987; Sanvido et al, 1992; Chua, Kog and Loh, 1999; Dainty et al., 2003) but the myriad of variables that have been derived from these studies have not yet led to any general agreement as to what constitutes project success. Typically this research has resulted in normative frameworks of success factors and criteria (Phua, 2003) which have been criticised as being incomplete and not specific enough for managers to act on (Zwikael and Globerson, 2006). In addition, they tend to focus upon specific aspects of construction projects, for example project partnering, construction contracting methods, planning and project management (cf Chua et al., 1999). However, Phua (2003) notes that multi-firm success can be agreed, at least at an operational level, as the extent to which projects meet a combination of budget, timetable and technical specifications. This indicates that there is not much focus on the wider success dimensions such as meeting the client objectives and ensuring that external stakeholders are satisfied with the project outcome.

A recent review of the literature related to CSFs in the field of construction management (Chan et al., 2004), demonstrates that factors can be grouped into five independent groups: human related factors (experience, client characteristics, project team), project factors (type, complexity, size), project procedures (procurement, tendering), project management actions (communication system, planning, control mechanisms) and external environment (social, economical, political). In this way, their conceptual framework acknowledges the 'hard' and 'soft factors' inherent in projects. 
Few studies focus on the design phase of construction projects. Current success frameworks do not seem to apply to this particular organisational setting which is often multidisciplinary and characterised by creativity, iteration and the uniqueness and temporality of project arrangements. In other words, the challenges that the project participants (engineers, architects, clients, contractors) face providing demanding services are many and varied (Koch and Bendixen, 2005). For example, there is a high degree of complexity and interconnectedness of tasks, a high dependence on diverse skills and collective knowledge and little time to find out where relevant knowledge resides (Cicmil, 2004). Teams often have difficulty developing a shared project vision since they tend to create their own understandings of the project reality based on their background and world view (Dogherty, 1992). Some writers have, therefore, justifiably described this type of consultancy as part of a broader business service sector, which can be regarded as knowledge intensive (cf. Koch et al., 1995). This context is, in a sense, unusual in that gauging the success of building design is usually more subjective during the design and construction phases than at a later stage when the cost-benefit analysis and client feedback is available (Allinson, 1997).

\section{METHODOLOGY}

\section{Research setting}

The study was based in a multi-disciplinary engineering consultancy in the UK, which employs 2000 employees in ten countries. The main engineering disciplines include: structural, building services and a number of specialist disciplines such as façade, fire and civil engineering. The engineering consultancy runs concurrently a large portfolio of projects and has a strong commitment to innovative solutions including research into sustainability and renewable technologies. Specifically, the investigation was located in an office in the South East of England which employs over 100 engineers plus of support staff. Typically each engineer is involved in two to seven projects simultaneously, reflecting a dynamic and busy work environment. Typically the firm will work with a separate architectural practice to provide the complete design team for a project. As a consequence of rapid growth over the past ten years, senior management has tried to find ways of improving the way projects and people are resourced and managed in order to improve performance and client satisfaction.

\section{Defining interdisciplinary design projects}

Design projects involve designers from various disciplines. According to Détienne (2006), two cooperative processes are of major importance in such multi-expertise tasks: coordination processes to manage task interdependencies (establishment of common ground) and negotiation mechanisms in order to manage the integration of multiple perspectives. Construction professionals often use the terms multi-disciplinary and inter-disciplinary interchangeable to describe the nature of their projects. The difference between the terms lies in the level of integration between professionals from different professional disciplines. According to MacMillan (2001, p. 187-188) a multi-disciplinary team denotes that there are several disciplines involved in a project, 'interdisciplinary design, by contrast may be thought of as occurring when problems are solved by the team as a whole, and where members are willing - and indeed are encouraged - to contribute... in areas beyond their own professions'.

In view of this, it becomes evident that building design is an outcome of interdisciplinary collaboration. However, in large design practices, cooperative work is often hampered by lack of time and resource but also cultural and professional barriers which make the team function more in a multi-disciplinary (individual delivery) rather than inter-disciplinary (integrated delivery) mode. This stresses the importance of managing task interdependencies and managing multiple perspectives Détienne (2006) to achieve successful collaborative design projects. 


\section{Data collection}

The research was carried out over an eleven month period: June 2005 - May 2006. A three-phase data collection strategy was employed comprising interviews, workshops and a survey. Initially, a series of semi-structured interviews were conducted with 22 engineers and CAD-technicians in order to examine the informants' current job roles and experience, employment history and time in the company and perceptions of what factors they think lead to project success. The sample selection was illustrative rather than representative responding to one of the tenets of conducting case study research (Yin, 1993). Thus, the major concern is more about generating a detailed examination of a single organisation and less about generalizability of the research findings. All interviews were recorded and transcribed verbatim. Since the aim was to reflect a broad spectrum of beliefs and values across the group, the sample was stratified to include individuals from different disciplines such as structural, building services and façade engineering. Six job levels were represented: group manager, associate, senior engineer, engineer, graduate engineer and CAD-technician. As part of the interview process, informants were asked to openly brainstorm critical success factors in project work. This was aimed to encourage individuals to 'make free associations' without being prompted about factors they perceive as critical to project success. The exercise was useful because it helped to reveal both the specific meanings that individuals attach to factors and their significance in the project context. This yielded a raw list of success factors (175) which were grouped into 29 primary CSFs categories reflecting a number of 'hard' and 'soft' constituencies that may influence project success (see Table 1, column A). 
Table 1.

An illustration of the evolutionary process of getting to the final set of CSFs.

\begin{tabular}{|c|c|c|c|}
\hline $\begin{array}{l}\text { Initial grouping of } \\
\text { factors }(A)\end{array}$ & $\begin{array}{l}\text { Workshops generic } \\
\text { categorisation (B) }\end{array}$ & $\begin{array}{l}\text { Internal survey } \\
\text { outcomes (C) }\end{array}$ & $\begin{array}{l}\text { Final synthesised list of } \\
\text { primary CSFs (D) }\end{array}$ \\
\hline $\begin{array}{l}\text { Comrnuric ation } \\
\text { Listering and feedback }\end{array}$ & $\begin{array}{l}\text { Communication } \\
-\end{array}$ & Communication & $\begin{array}{l}\text { Rich communications } \\
\text { Regular feedback on } \\
\text { progress }\end{array}$ \\
\hline Skillsle xpertise & $\begin{array}{l}\text { Competencies (social and } \\
\text { technical) }\end{array}$ & $\begin{array}{l}\text { Social skills } \\
\text { Techrical skills }\end{array}$ & $\begin{array}{l}\text { Social skills } \\
\text { Technical skills }\end{array}$ \\
\hline Motivation & Motivation & Motivation & Motivation \\
\hline Passion and enthusiasm & - & - & Passion and enthusiasm \\
\hline The challenge & - & - & Challenging projects \\
\hline Recognitionlappreciation & - & - & Recogrition'appreciation \\
\hline Quality of leadership & $\begin{array}{l}\text { Leadership (high level, } \\
\text { strategy, vision) }\end{array}$ & Leadership & Quality of leadership \\
\hline- & General manage ment & Project manage ment & $\begin{array}{l}\text { Project manage ment } \\
\text { practices }\end{array}$ \\
\hline Resources and planring & Resources stuff & Resources & Sufficient resources \\
\hline Cooperationicollaboration & Team stuff & Teamwork & $\begin{array}{l}\text { Effective inter-disciplinary } \\
\text { team working }\end{array}$ \\
\hline Relationships & Extemal influences & - & Relationships \\
\hline Group development & Social activities & Social activities & Team building process \\
\hline $\begin{array}{l}\text { Trust and respect } \\
\text { Mutual understanding }\end{array}$ & - & Trust & $\begin{array}{l}\text { Mutual trust and } \\
\text { understanding }\end{array}$ \\
\hline $\begin{array}{l}\text { Team selection and } \\
\text { composition }\end{array}$ & - & - & $\begin{array}{l}\text { Team selection and } \\
\text { composition }\end{array}$ \\
\hline $\begin{array}{l}\text { Clear roles and } \\
\text { responsibilities }\end{array}$ & - & Roles and responsibilities & $\begin{array}{l}\text { Defined roles and } \\
\text { responsibilities }\end{array}$ \\
\hline $\begin{array}{l}\text { Definediclear goals and } \\
\text { project vision }\end{array}$ & - & Defined project goals & $\begin{array}{l}\text { Defined project goals } \\
\text { Shared project vision }\end{array}$ \\
\hline Culture & - & Culture & Culture \\
\hline- & - & Shared values & Shared values \\
\hline $\begin{array}{l}\text { Organisational } \\
\text { context/structure }\end{array}$ & - & - & Organisational structure \\
\hline Technology & Supporting technologies & Technology & Appropriate technologies \\
\hline Physical ervironment & $\begin{array}{l}\text { Physical office } \\
\text { environment }\end{array}$ & Office environment & Physical work environment \\
\hline Profit and financial & - & Commercial awareness & Cormmercial awareness \\
\hline Knowledge management & - & Knowledge management & Knowledge sharing \\
\hline $\begin{array}{l}\text { Innovative } \\
\text { thinking/creativity }\end{array}$ & Creativity and innovation & Creativity and innovation & Creativity and innovation \\
\hline Time management & - & - & Time management \\
\hline Change and flexbility & - & - & $\begin{array}{l}\text { Change management and } \\
\text { flexbility }\end{array}$ \\
\hline Perceptionjexpectation & - & - & $\begin{array}{l}\text { Management of } \\
\text { expectations }\end{array}$ \\
\hline Work processes & - & - & - \\
\hline Good contractor & - & - & - \\
\hline
\end{tabular}


The main aim of the workshops was to validate the interview data in terms of the classification of success factors. However they also provided an opportunity to involve more engineers and CAD-technicians in the research. Thirty six participants were recruited to take part in the exercise. They were put into groups of 4-6 people according to their job level and given 45 minutes to complete the task of coming up with their own grouping and labelling of success categories, as shown in Table 2. The workshop outcomes and the 13 generic success categories created to summarise their result can be seen in Table 2, column A and also in Table 1, column B. Having completed the analysis of the workshops a new set of 21 primary CSFs was developed which appear in Table 1, column C.

The third phase of the data collection was to conduct a survey of the revised set of 21 CSFs . The purpose of the survey was to make a quick assessment of how the participants rate these factors in terms of their importance for project success. In other words, the aim was to establish whether some factors are more relevant than others rather than making any statistical claims about the data themselves. In addition, it enabled the researchers to provide feedback to the wider group on the nature of the factors that are considered as 'critical' in order to achieve project success. The survey was sent out to all practitioners and managers within the multidisciplinary business unit (108) via e-mail asking them to rate the factors using a 1-10 rating scale. The results (44\% response rate) indicated that the factors are highly interrelated. For example, most factors were perceived as 'highly important'. The only factor that was rated as 'less important' was 'social activities'. The survey was an important step for consolidating the previous analysis and helpful in developing the final factor groups. 
Table 2. Representing the grouping and labelling of CSFs by six different job levels (workshop outcome)

\begin{tabular}{|c|c|c|c|c|c|c|}
\hline & Job levels & & & & & \\
\hline $\begin{array}{l}\text { Generic } \\
\text { wodshop } \\
\text { cadegories }\end{array}$ & Group manages & $\begin{array}{l}\text { Associate } \\
\text { engineers }\end{array}$ & $\begin{array}{l}\text { Senior } \\
\text { engineers }\end{array}$ & Engineers & $\begin{array}{l}\text { Graduate } \\
\text { engineers }\end{array}$ & $\begin{array}{l}\mathrm{CAD} \\
\text { technicians }\end{array}$ \\
\hline $\begin{array}{l}\text { General } \\
\text { mamagement } \\
\text { Leadershị } \\
\text {-- }\end{array}$ & $\begin{array}{l}\text { Management } \\
\text { (process) } \\
\text { Mamagement } \\
\text { (people) } \\
\text { Leadership } \\
\text {-- }\end{array}$ & $\begin{array}{l}\text { Mamagement } \\
\text { (process) } \\
-- \\
\text { Mamagement } \\
\text { Meadership } \\
\text { Forward } \\
\text { plaming }\end{array}$ & $\begin{array}{l}\text { Leadershị' } \\
\text { Mamagement } \\
--\end{array}$ & $\begin{array}{l}\text { Project } \\
\text { mamagement/' } \\
\text { project delivery } \\
- \text { Leadershị } \\
--\end{array}$ & $\begin{array}{l}-- \\
-- \\
\text { Mamagement and } \\
\text { leadership } \\
\text { Strategy and } \\
\text { direction }\end{array}$ & $\begin{array}{l}\text { Project } \\
\text { leadership } \\
\text {-- } \\
\text { Leadershị } \\
--\end{array}$ \\
\hline $\begin{array}{l}\text { Corrmouricatio } \\
n\end{array}$ & Corrmunication & Conmounication & Corrmounication & -- & Cormmunixation & $\begin{array}{l}\text { IT and } \\
\text { infomation }\end{array}$ \\
\hline Team stuff & Team working & Team factors & Team dynamiss & $\begin{array}{l}\text { Project team } \\
\text { interaction } \\
\text { The design team }\end{array}$ & $\begin{array}{l}\text { Project team } \\
\text { composition }\end{array}$ & The team \\
\hline $\begin{array}{l}\text { Motivation } \\
-- \\
-- \\
--\end{array}$ & $\begin{array}{l}\text { Motivation } \\
-- \\
-- \\
--\end{array}$ & $\begin{array}{l}\text { Motivation } \\
-- \\
-- \\
--\end{array}$ & $\begin{array}{l}\text { Motivation } \\
-- \\
-- \\
--\end{array}$ & $\begin{array}{l}\text { Incentives } \\
\text { Warting to be } \\
\text { involved } \\
\text {-- }\end{array}$ & $\begin{array}{l}-- \\
-- \\
- \\
--\end{array}$ & $\begin{array}{l}\text { Work } \\
\text { satifaction } \\
\text { Heeds and } \\
\text { understanding }\end{array}$ \\
\hline $\begin{array}{l}\text { Cormetencies } \\
\text { (social and } \\
\text { techmical } \\
\text { skills) }\end{array}$ & Corretency & Individual skills & -- & -- & $\begin{array}{l}\text { Individual } \\
\text { capability }\end{array}$ & -- \\
\hline $\begin{array}{l}\text { Social } \\
\text { activities }\end{array}$ & Social & -- & - & -- & -- & - \\
\hline $\begin{array}{l}\text { Physical work } \\
\text { ervironment }\end{array}$ & $\begin{array}{l}\text { Physical offioe } \\
\text { enviromment }\end{array}$ & $\begin{array}{l}\text { Office } \\
\text { ervinonmert }\end{array}$ & -- & -- & -- & -- \\
\hline-- & -- & Culture & Culture & $\begin{array}{l}\text { Compary } \\
\text { lorganisation }\end{array}$ & Culture & Culture \\
\hline Client focus & -- & $\begin{array}{l}\text { Cliert brief' } \\
\text { knowledge }\end{array}$ & Client focus & -- & -- & -- \\
\hline $\begin{array}{l}\text { Supporting } \\
\text { techologies }\end{array}$ & -- & Tectmobgy & - & - & -- & -- \\
\hline $\begin{array}{l}\text { Extemal } \\
\text { influenoes }\end{array}$ & - & $\begin{array}{l}\text { Extemal } \\
\text { influenoes }\end{array}$ & -- & - & Extemal & $\begin{array}{l}\text { Extemal } \\
\text { relationships }\end{array}$ \\
\hline $\begin{array}{l}\text { Creativity and } \\
\text { innovation }\end{array}$ & -- & $\begin{array}{l}-- \\
--\end{array}$ & $\begin{array}{l}\text { Irmovation } \\
\text { Engineering } \\
\text { design }\end{array}$ & -- & -- & $\begin{array}{l}-- \\
--\end{array}$ \\
\hline $\begin{array}{l}\text { Resouroes } \\
\text { stuff } \\
--\end{array}$ & -- & $\begin{array}{l}-- \\
--\end{array}$ & -- & $\begin{array}{l}\text { Time resource } \\
\text { Techmical } \\
\text { resources }\end{array}$ & $\begin{array}{l}\text { Time } \\
\text { Physical } \\
\text { resources }\end{array}$ & -- \\
\hline-- & -- & -- & -- & -- & $\begin{array}{l}\text { Human } \\
\text { resources/ } \\
\text { support }\end{array}$ & $\begin{array}{l}\text { Individual } \\
\text { leadership } \\
\text { and support }\end{array}$ \\
\hline-- & -- & -- & -- & -- & $\begin{array}{l}\text { Financial } \\
\text { awareness }\end{array}$ & -- \\
\hline
\end{tabular}

\section{Data analysis}

The overall analytical approach of the interview data largely followed the steps of thematic analysis (c.f. Boyatzis, 1998), where the data is systematically coded and grouped into meaningful categories which represent the raw data. This iterative process (as shown in Figure 1) allowed the data to lead the study, so each step built upon and added data and enlightenment in a continuous process of re-visiting data, followed by analysis and better understanding.

The process of creating the raw list of CSFs, which comprised of 175 (some overlapping) factors, involved repeated rounds of reading the textual data (responses of the interviewees) to elicit and formulate appropriate codes. Most of the factors identified were descriptive, requiring 
little or no additional analysis although some were more interpretative and therefore harder to define clearly. These included issues relating to interviewees feelings about what is really important to them in achieving success (e.g. affiliation to the project, ownership, intrinsic motivation). Once the coding process was completed and duplicate factors were removed, a revised list of factors was produced and subsequently grouped into the initial 29 high level categories as can be seen in Table 1, column A. Overall, the table depicts the process and thus the evolutionary understanding of what constitutes success factors within interdisciplinary projects. Importantly, it shows that the final 31 CSFs were developed as a result of triangulating and making sense of the three data sets (see Table 1, column D).

The development of the four CSF factor groups was based on a synthesised interpretation of the overall data including comparison with existing recent literature reviews of CSFs and project success (Jugdev et al, 2005; Fortune et al, 2006). No particular relevance was given to frequency in terms or repetition of ideas or concepts. Often, the same participant referred to the same CSF more than once in his/her response by rearranging the words or emphasising a particular point. Equally important, although a particular factor was only mentioned by one participant this factor was not necessarily seen as irrelevant.

Figure 1 illustrates the process of creating the final sets of CSFs which underpin project success in such project endeavours. While the iterative process of refining and modifying the factors could not be adequately captured and shown graphically (ie the merging and/or splitting of factors), the table provides an overview of recurrent themes and idiosyncratic factors that are relevant in complex project settings such as inter-disciplinary design. The 31 primary CSFs emerged around four main factor types (or themes) explicated below; management factors, design team factors, competencies and resources factors and project enablers.

'Take in Figure (No 1)'

Figure 1. The research process.
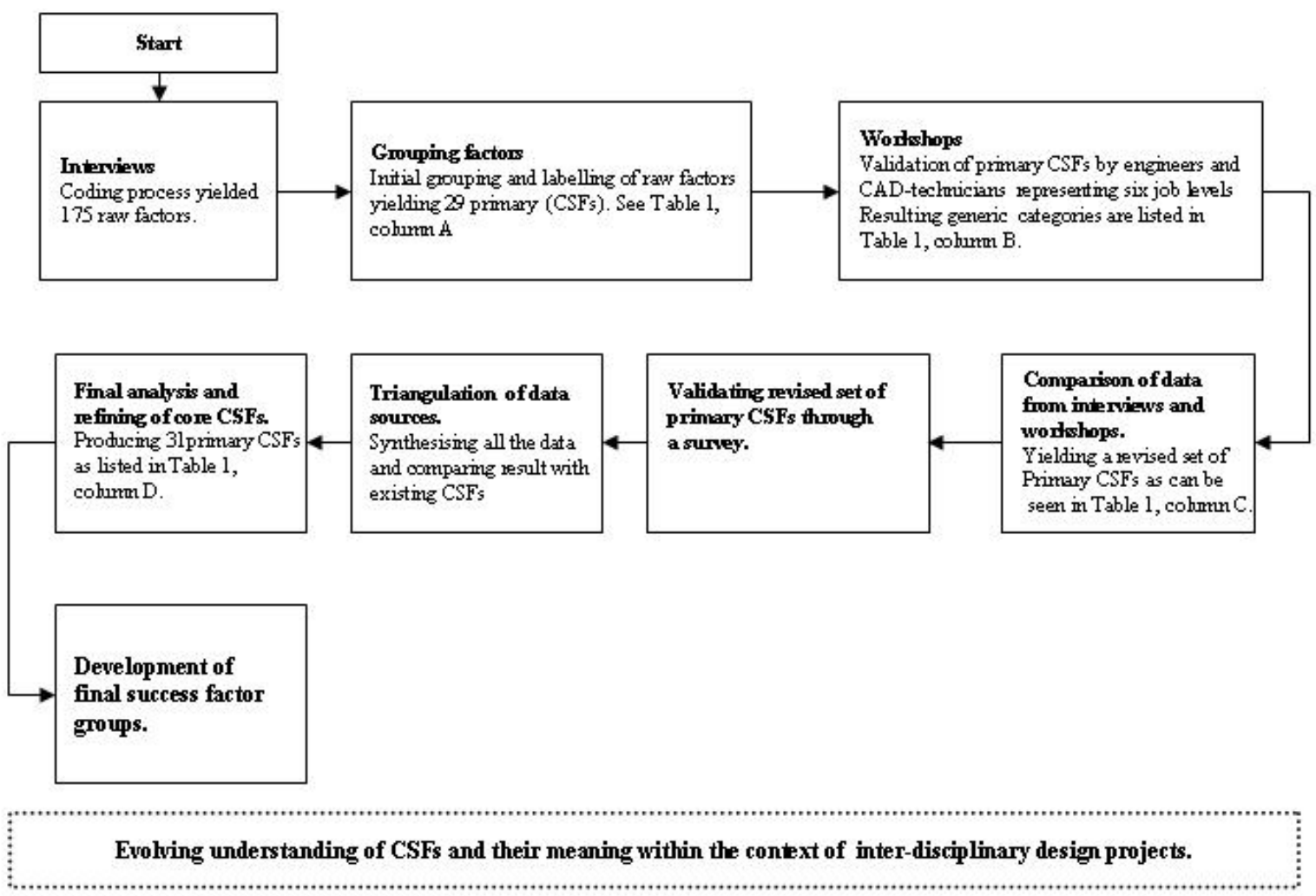


\section{RESEARCH FINDINGS}

To present the analysis of the overall results, the results are divided into five sections. The first section is concerned with providing an overview of the general perspectives on CSFs and the clustering of CSFs and the remaining four will cover the main CSF groups. The final grouping of CSFs into main factor groups is represented in Table 3, and is intended to show the factors that project participants (engineers and technicians) perceive as relevant to successful project delivery as a whole. Essentially, the final formulation of factor groups is based on an overall interpretation of the conditions that shape implementation and management of multi-disciplinary projects as identified by the practitioners themselves.

Table 3.

A representation of the final four interdependent factor groups and the underlying CSFs.

\begin{tabular}{|c|c|c|c|}
\hline Manage ment issues & Design team issues & Competencies and resources & Project enablers \\
\hline Defined project goals & Shared project vision & Technical skills & Rich communications \\
\hline Defined roles and responsibilities & Team selection and composition & Social skills & Passion and enthusiasm* \\
\hline Project manage ment practices & Team building process & Change manage ment and & Challenging project \\
\hline Quality of leadership & Inter-disciplinary team working* & flexibility & Recognition \\
\hline Management of expectations & Creativity and innovation* & Time management & Motivation \\
\hline Feedback on progress & Relationships & Appropriate technologies & Organisational structure \\
\hline \multirow[t]{5}{*}{ Commercial awareness } & Mutual trust and understanding & & Culture \\
\hline & Sufficient resources & & Knowledge sharing \\
\hline & & & Client focus \\
\hline & & & Physical work environment \\
\hline & & & Shared values* \\
\hline
\end{tabular}

CSFs which are important in inter-disciplinary design projects that do not figure in other studies of project success factors.

\section{General observations on CSFs}

When asked to openly brainstorm what factors are critical to project success, participants made reference to both CSFs (i.e. what they think is important to achieve project success), and success criteria (i.e. the standards by which they judge the completed project). These two concepts were used interchangeably in order to paint a broad picture of 'success', demonstrating that there is confusion as to what exactly defines 'critical success factors'. For example, reference to 'relationships' was used to illuminate both its strong influence in keeping the project participants interested and motivated in the project process, but also as an important indicator of whether the project was successful in terms of improving internal or external relationships. These results appear to confirm findings from other research projects in this area such as de Wit (1988) and Cooke-Davies (2002) that success factors and success criteria are interrelated. In addition, most practitioners identified a variety of factors by sharing their personal experiences of 'successful' and 'unsuccessful' design projects. Specifically, CSFs were talked about in terms of what 'must be in place' or actions that has to be taken; 'you must' lists; for example 'you must have agreed objectives and a shared project vision for it to work better'.

In line with existing research across different industry sectors the factors are highly interlinked, context-specific but also influenced by the practitioners' actions (Nandhakumar, 1996; Cooke-Davis, 2002). For example, issues concerned with the 'design team' are clearly related to those of management and communication. Similarly, issues of motivation in the design process are clearly related to those of leadership and shared project vision. Further, many of the wish list factors are themselves in tension with each other. For example, the importance that practitioners place on 'interdisciplinary collaboration', tends in practice to be in tension with 
'contractual arrangements' or 'participant-personalities'. Analysis of the research data also reveal complexities in dimensions to do with inter-disciplinary projects which have not directly emerged from practitioners as themes but which cut across all of them. For example, the analysis of the CSFs revealed that inter-disciplinary projects are often ill defined, complex and inherently dynamic structures in which participants continually have to deal with uncertainty and emerging issues. This is significant because it impacts upon all of the other factors and contributes to making interdisciplinary design projects complex endeavours.

The main findings of the survey (rating of 19 factors) helped to further modify the list of salient CSFs distilled from the initial grouping and the workshops. By including new factors in the survey such as 'project management' and 'benchmarking' (later subsumed under 'knowledge sharing', see Table 1) it became evident that these were missing and should be incorporated in the list of CSFs. Above all, the survey highlighted factor interdependencies which may explain the difficulty in deciding which factors are more important than others. The only factor which was rated as less important for project success was 'Social activities'. Although it was strongly implicated in the interviews, it is clearly seen as peripheral to the core activities of project work. Thus, social activities represent a 'wish-for-factor' rather than an 'absolutely-necessary-factor'. However, since there is an obvious link with Group development (initial CSFs list in Table 1) it was modified and subsumed under Team building process (see primary CSFs in Table 1). An interesting finding was that 'client focus' emerged as more important in the survey than it did in the interviews which may indicate that engineers and CAD-technician are more interested in the project task than the client. In reality, consulting engineers are appointed by the architect who then becomes the client handling the client(s); the person(s)/companie(s)/government who is commissioning the building. From this perspective, the client as well as other factors of the project environment such as supply chain, legislation and so on do not seem as critical until they are pointed out.

\section{Perceptual differences of success factors}

The study revealed areas of both differences and similarities in the perceptions of CSFs and success among project participants. Generally the perceptions of CSFs for project success vary little across the engineering disciplines as can be seen in Table 1. Variations between groups appear to be a consequence of job roles rather than professional disciplines. In broad terms, group managers and associates appear to look at what they want from their teams in terms of competencies and profit, the middle level (senior engineers and engineer level) are more focused on project delivery and operational issues, and the junior staff on learning and what they need to deliver as members of the team. Consequently, junior and middle level engineers seem more committed to the project as a career progression than to the organisation (company) itself. This may explain the importance that is placed on having the opportunity to work on different projects with different architects.

The technicians seemed to focus more on effective communication and project leadership as well as having the right technology to respond to client requirements. They also seem more concerned about working in a supportive environment where their needs of inclusion and being part of the team are being met. These observations suggest that even within the core engineering design team itself (excluding client, architect, contractor etc) practitioners have different perceptions of success and success factors.

A striking observation was that when given the freedom to state any success factor, most respondents emphasised variables relating to the internal characteristics of the project process such as team working, clear understanding of their role and responsibilities. There was little reference to external variables such as 'customer focus' or 'client satisfaction'. A similar pattern of responses was recorded in the subsequent workshops. Contrary to recent literature on project success factors (e.g. Meredith et al, 2006), client focus does not emerge as a priority for a successful project delivery. This brings attention to the specificities of multi-disciplinary project delivery in construction related organisations. While it appears possible to meet both internal (e.g. cost, time and to specification) and external goals (client satisfaction), when faced with 
pressure, project participants pursue their own goals sometimes with little explicit regard to the customer. This result resonates with findings in other engineering contexts such as systems development (e.g. Wateridge, 1995) and illustrates a common reality in the so called expert organisations (Lowendahl, 2005; Delong and Fahey, 2000). In other words, the structure of work and the pressures that most often plague design environments (e.g. being involved in two or more projects simultaneously), encourages action rather than reflection, meaning that the 'the client' is crowded out by more immediate concerns. One, senior building services engineer, expressed it as:

You just work, work, work, busy, busy, busy you know. I can organise my time but then somebody throws something in... something is coming from nowhere, which should not happen really.

In the excerpt above, the engineer depicts the challenges of achieving project success consisting of issues in the organisational context, which he describes as 'busy, busy'. This issue demonstrates a project-centric culture where there is an overwhelming tendency for managers to get caught up in 'fire-fighting'. Conversely, although the dynamics of design work undoubtedly influences project success, it appears that care for the client emerges as a result (by-product) of working together as a team. As expressed by an associate engineer:

'More client focus does not make the project anymore profitable but greater collaboration does'

Evidently, there is a willingness to collaborate among practitioners, which means that there is a belief that people and their ability to work together strongly influence project outcomes in many ways.

In generic terms, project participants tend to differentiate between what is important to keep the project momentum going which can be termed organisational catalysts and what appears important to keep the team close together throughout the troughs and peaks of the project which is summarised with the realm of management practice; clarifying the what (aims and goals), when (work schedule) and how (process and support) of the project is important. Therefore as is seen repeatedly through the following sections, there are many factors that impact on project success, but most importantly as participants talk about their perceptions of 'what must go right' there is also an honest and deep concern about 'how to get it right'. While there is an acknowledgement that management is important, there is also a perception that engineers lack the training to deal with the gray and vague issues of business management. As explained by a senior engineer:

'Most of the associates and beyond are engineers and not managers. I don't think that they have the techniques to manage and I don't thing they have the skills they need because like me they are brought up in an engineering environment'.

In other words, engineers and technicians are identifying the need for technical as well as management knowledge to achieve project success.

Overall, it was difficult to identify the potential contribution of each factor independently because many factors influence practitioners' activities at the same time. This is confirmed by studies in other project environments such as information systems implementation (e.g. Nandakumar, 1996). For instance, it is not possible to talk about clear goals without talking about communication or about creativity and innovation without mentioning resources. From this perspective, project outcomes are a result of mutually determining processes in the project environment. In brief, the factors relating to the design team processes incorporate the skills of the individuals as well as the functioning and development of the team. The factors linked to management process are related to leadership of the project and people as well as project planning and control. Finally, the catalyst factors are linked to elements that underpin the 
performance of the other CSFs. These are linked to communication, knowledge sharing, leadership and enjoyment/intrinsic motivation.

The next section delineates the four factor groups that are seen as integral to project success as a whole.

The main outcomes of the survey were that all factors except 'social activities' were rated as 'highly important' indicating that factors that are more directly related to completing the project are seen as more important than factors that are it is within the project context. Since the survey also provided an opportunity for respondents to add factors, this helped to consolidate and/or slightly modify the results from the interviews and workshops.

This was taken as enough evidence to suggest that any success framework has to be built on the idea that projects made up of different systems of activity that are constantly interacting and influenced by their environment.

\section{Design team factors}

Team work and relationships are used interchangeably to illustrate the importance of interaction between individuals in successful design projects. Specifically, it shows that one dimension of project success is measured in terms of team success or the outcomes of team work. For instance, even if the project has failed in terms of meeting the basic standards of success such as cost and time, the project may still be seen a success in terms of team work or 'forming good relationships with the architect'. From the accounts, especially from the senior engineers and above, it is clear that quality of relationships (that develops between project members) is perceived to indirectly influence project outcomes. It affects the team effort and is thus important to achieve the project objectives. This can be seen in the following extracts by two different group managers:

'You can have projects where you can look forward to the project meetings and it doesn't mean that the meetings are going to be easy but it means that you are going to enjoy the company and that is ok, because if the project is worth doing you don't mind it being tough. It is simple really, successful project benefits from a team that is enjoyable to be with'.

'I could easily persuade myself at the moment that if you have a good team, pulling in the same direction, it will go very well, but the building might not be any better...but you will have got there will less stress and probably would have made more money because the team members were not fighting amongst themselves'.

In this context, the notion of 'working as team' was a recurring theme. On a general level, achieving genuine integration between experts from different disciplines was defined as a critical ingredient in achieving both project and team success. However, the issue of teamwork and relationship building is often crowded out by the project tasks themselves. The paradox is that while it is the tasks that bring the different disciplines together, little time is spent in integrating the team effort as part of normal practice. An engineer explains:

Our projects are really good where we manage to achieve integration between structures, services and civil engineers, but unfortunately that does not always happen because there is no time to for it or there is change of personnel. I think that more effort is needed to foster good relationships from the beginning.

However, putting individuals from different backgrounds together will not automatically generate the synergy that will result in project success (Newell et al, 2002). Structural engineers, building services engineers, technologists and architects usually speak different 'languages' and 
do not readily understand the problems of the other (see, e.g. Dougherty, 1992). The complexities arising from collaborative working relationships are present in the interviewees' pre-occupations and concerns and were expressed in terms of CSFs such as: integration between disciplines, team building processes, relationships and mutual understanding and respect between people. In the literature relationships are increasingly cited as an important factor in for the successful management of projects across industries, not the least within construction (Pryke et al., 2006). Creating and maintaining effective relationships within a project team, however, depends on more than simply social skills which enable team to 'get along' with each other; it requires concerted action within the team. As expressed by an engineer:

'It is important that the team bond together. It is about forming relationships. If you know somebody they are more likely to help you. Taking time to get to know people is important, eg having drinks after the first meeting etc'.

On a deeper level, this reflects and affects the practice culture. As noted by Holland et al (2000) in their review of CSFs for cross functional team work: 'teams adapt to their environments, becoming the kind of a team that their organisation will tolerate, while through their boundary spanning activities, they also alter their context. In order to overcome the problems of collaborative team working, managers should not only focus on building attachment to personal and financial goals, they also need to ensure that they build a safe and secure environment in which individuals and teams can work effectively together (Staples, 2004). Generally, interviewees agreed that team building has to happen as early as possible in the project life cycle to create mutual trust and respect as well as positive emotion. As noted by one senior engineer:

'You have to get an understanding between the architect and all the others; you have to work together as a team'.

Further, the experiences of team work as an important factor for project success was not only described in terms of 'having a good team with individuals who complement each other', but also as a vehicle to improving communication, knowledge sharing, team bonding and getting project participants enthusiastic about the project. In this way, 'team work' is a factor that comprises the factors that make up the psycho-social environment, providing a sense of inclusion and emotional support to the project members (Stapley, 2006). However, collaboration and team work does not happen automatically, at least not in multi-disciplinary teams where individuals are located in different office spaces and issues of hierarchy and status matters.

\section{Management factors}

Practitioners identify leadership and project management as pivotal for successful project outcomes. The leadership dimensions were focus on people and focus on project processes and include effective project management, clear goals, roles and responsibilities, scope of work, regular feedback on progress, commercial focus and management support. The management dimensions include the operational running of the project as well as the direction of the project coalition as a whole. This is a particularly difficult process that requires strong and supportive leadership in term of giving the professionals' freedom and autonomy in the project process, rather than imposing too many rules and regulations which may constrain the 'work flow'. It is therefore not surprising that all interviewees identified CSFs in this cluster. As expressed by a group manager in the following extract:

'Important to success is those things than I call 'managementy' sort of things that actually make a real difference such as management of resources'.

The strong emphasis on management and leadership issues draws attention to the fact that, it is essential to acknowledge the influence that a leader has on the project process and levels of 
motivation. Here project members indicated that team leadership is not as strong as it could be. Implied in what the engineers and technicians report is that existing management practices or lack thereof have an effect on the psychological well being of the individual and the group. A sense of concern is expressed by particularly mid-level engineers and generally among CADtechnicians regarding leadership abilities, as shown in the following extract:

'Most of the associates and beyond are engineers and not managers. I don't think that they have the techniques to manage and I don't thing they have the skills they need because like me they are brought up in an engineering environment'.

Further, most participants did not necessarily view project management as a set of techniques to deliver the project on time, within budget and to specification. From the accounts it is clear that they see it at as hands-on tasks that make the project delivery process smoother.

As one structural engineer explained:

'To keep an eye out and knowing when to step in and support the team, to make sure you are getting down the right route, to be completely up to speed with the project and aid the coordination process and to help with the communication between the different disciplines'

Of particular note here is that engineers and technicians differentiated between 'leadership functions' (establish direction, vision for the future, aligning people, motivating and inspiring, satisfies human needs); and 'management functions' (plans and budgets, decides actions and time tables, allocates resources, organising and staffing, procedures and monitoring projects, controlling, problem solving, takes corrective actions). Senior levels perceived these roles as integrated rather than separate whereas more junior staff viewed them as relating to organisational organisation and culture. This shows that project participants have different perceptions of these organisational concepts. Another interpretation may be that that there is a lack of understanding among engineers and technicians as to what management entails. This confusion may stem from the particular way that projects are structured in terms of accountability. Within the context of the case study company the management structure consists of a project leader, who is responsible for the operational running of the project internally and who reports to the project director. Below the project leader is the job leader who is responsible on a discipline level (e.g. structural, services engineering).

Although there was a strong perception that the introduction of more effective ways of planning and controlling of design projects may affect project success, the informal means of control, i.e. the ad hoc meetings and conversations rather than formal procedures, is the preferred way of managing the project. However, there was a tension between the need for more 'organisation' in terms of supporting technology for planning and work break down and the preference of individuals to run their projects as they are used to; through non-standard procedures. As one senior engineer explained:

'Project management is most often left to individualistic initiatives of engineers rather than the systems and procedures that are suggested by the quality management...'.

Studies that focus on professional cultures such as engineering and other consulting environments have shown that 'experts' (knowledge workers) operating in such settings often pay little attention to management. They are often given managerial roles on the basis of their technical skills and merit rather than heir interest and appreciation of management (see, e.g. Lowendahl, 2005). Therefore, the role of project manager/leader has to be communicated more clearly to in order to get buy-in from the project community.

\section{Competencies and resources factors}


Engineers also regard technical skills as critical in achieving successful projects. Therefore, 'design competency' and experience were identified as CSFs. Simply put, technical expertise is perceived as the foundation for all creative design engineering work. However, successful engineering also depends on what happens in the early stages (conceptual and scheme) of design. At these stages the engineers and technicians have the opportunity to influence the architecture and fix the most important engineering fundamentals. Most importantly, the early design stages enable the engineer to think creatively and express workable solutions which makes it one of the most satisfying part of the design process. Thus being able to spend time testing different ideas is seen as particularly important especially for junior to senior level engineers. As one structural engineer expressed:

Looking at my successful and unsuccessful projects, we seem to work better in projects where we do get to be a bit more innovative, where the architects will allow us to have a broad role in the project.

But there was also recognition that social skills are important to achieve technical excellence. For example, given the way in which decisions are made within the team, political skills play an important part. This is reported as an important 'soft skill' that only a few engineers have. These results are not extraordinary and seem to reveal a certain degree of maturity in the field of engineering design projects. Engineers and CAD-technicians are well aware that most engineering output is governed by 'personalities' and relationships amongst the design team members. As senior engineer explains:

'You have to be a good engineer and know what you are doing and that includes other skills as well such as communication skills. Technical skills can only take you so far it I is not enough to achieve success...'.

More junior engineers perceived technical skills as a broad category, including creativity and opportunities to produce innovative and sustainable design solutions. From the perspective of the most senior engineers competence is perceived as a competitive advantage; 'where we can differentiate ourselves from other companies'.

Having sufficient resources is also reported as extremely important and it refers to both human (enough people involved in the project) and physical resources such as technology and systems. This need is articulated across disciplines, which can also be interpreted as better management of resources. Further, it relates to team effectiveness and teams need time to pursue their tasks. From this perspective, organisations must provide support or the application of resources critical for individual to apply their expertise and team effectiveness. In this context, reference is also made to how much the client is prepared to spend on the project, which represents a resource factor outside the control of the engineers. There is always a tension between how much money can be spent on the project and the aspirations of the engineers. However, resources for the engineer is linked to adequate project fee, whereas for the technician is mostly related to having appropriate technology to complete the drawings. One structural engineer said:

Having enough time to do the design is crucial. Quality design comes out of having time to think about what you are doing. In a sense there is a need for more organisation [of the design activities] to free up more time.

The pressure to deliver 'more for less' is described by many practitioners as 'the way the construction industry is going'. Consequently, there is a commonly held view by practitioners that there will always be a resource problem in design project work. However, there is also a 
tension between what can actually be delivered and the constraints of a small budget, as is observed by one senior engineer:

'How are we supposed to be successful when the fee is too low? That is a major constraint in a lot of project work and it means that we cannot spend much time on it; not to mention meeting the other people on the team'.

\section{Project enablers}

This cluster encompasses the subset of CSFs that are perceived to influence all the other project success factors. The factors in this domain underpin the performance of other success factors and thus impact on the overall project success. In other words, they form the backbone of interdisciplinary project performance. For example, communication is perceived as the essential enabler of managing change as well as the team and project members 'have to be able to communicate design' as it were. The problem in most projects is the lack of rich communications between project participants, which may lead to disintegration and low trust project coalitions. One of the most frequently used sub meanings in relation to communication was 'clarity'. This was defined by the participants as the level of information they have about the project, their responsibilities, and whether the project goals are readily understandable.

Additionally, this relates to being clear about what the technical issues are, which presents an important 'support' mechanism for the individual engineer and technician in the on-going project process. As one of the associate structural engineers put it:

Clear scope of work, clear brief, clear programme, budget, timing /.../ it is kind of clear everything! So clarity is incredibly important for project success.

Following this, unsurprisingly, communication was singled out as the major 'catalyst' for all CSFs. At the same time failure to communicate seems to be the root cause of many project failures. This means that there is a need to increase awareness of CSFs and their interrelationships within the project context. For example, communicating the project goals is not only important for the project it also has implications for how the group will interact. Having a clear idea of roles and responsibilities within the project early on is deemed important. The respondents, regardless of job level or discipline reported this as critical for the ability to prioritise their involvement in other projects as well as knowing what their particular contribution will be in a particular project.

However, practitioners also recognise that communication has to be embraced at all levels in practice. As one senior building services engineer explains:

One of the problems is that the management does not communicate amongst themselves which is not ideal when you are working across a number of projects which means that you get conflicting 'orders'.

In light of this, rich communications is seen as intrinsically worthwhile within the team in order to create mutual trust between the different team members. For example, communication and integration were sometimes used interchangeably, across the job levels, which show that rich communications is believed to contribute to breaking down discipline as well as hierarchical barriers.

Another important catalyst which was widely expressed as a CSF was the project/task itself. This means that the more interesting the project is, or using the words of the practitioners; has the 'wow-factor', the more likely it is to engender commitment in terms of resources and enthusiasm is invested. Similarly, the opportunity to work across a number of different 
interesting projects is seen as an important driver of success. One of the building services engineers mentions:

The type of project matters for project success. I don't like working common projects like ware houses or shopping centres.

In a sense the on-going project has to satisfy the project members in certain ways, which inevitably impacts on the wider perceptions of project success (the completed building). But what motivates one individual does not necessarily motivate another. Budget and profit does not increase motivation per se but if it means that it allows the members to spend more time on refining and working on the design, it is critical to the design process. However, motivation can be affected by a number of external factors which are linked to 'project delays' and 'frequent changes of personnel'. Another important factor in this category is the motivation of the project members in terms of their willingness to work and feel 'passionate' about what they are doing.

'I think that a perfect project is one where you can somehow manage to get the engineer to be involved early on so that he or she ends up feeling passion for the project' (Associate structural engineer).

On a general level, the experience of 'passion for the project', 'enthusiasm' and 'having fun' emerges as critical to both individual and collective success. It represents the assortment of intangible CSFs which influences the way the total project success is perceived. These results seem to confirm findings from research projects in other organisational environments. For example, according to Gratton (2007) as people feel increasingly passionate about something, they really care, and they enjoy the emotional contagion as others becoming engaged and excited. This is shown in the following extracts:

'At the end of the day I guess you have to be enthusiastic about it...you have to want to do it'. (Associate engineer)

There are difficult times in all projects even if you have all the CSFs in place, but if the team or the leaders of the team have the passion to want to do something better then you stand a higher chance of it to happen. You got to have passion to finish something that is worthwhile. (Group manager)

In this way, achieving success in interdisciplinary projects is heavily dependent on the level of positive emotion as experienced by the project members.

\section{Using Formal Systems Model to display factor interrelationships}

Whilst the core of the study was to identify CSFs in inter-disciplinary projects, what surfaced time and time again in the research process was that it is impossible to reduce success to a number of finite factors. In addition, since it appeared difficult to isolate them, it was contended that it is more useful to view the factors as interdependent elements in the organisational environment. A systems model, the Formal Model was used to display these important interrelationships. This is based on the notion that becoming better in systems thinking helps people to 'see' underlying activity systems driving behaviour and performance (Senge, et al., 1994). Whilst the model does not take sufficient account of the socio-political factors which reside within multi-disciplinary design projects it provides a holistic framework for making sense of project outcomes.

Table 4 shows a mapping of the components of the model and the identified CSFs identified in the present study. Figure 2 is an illustration of the FSM which will be essential in the follow up study of project success in interdisciplinary design environments. It shows the different levels of organisational systems and their interrelationships and the influence of the 
environment. From this perspective, the model may be used by practitioners as a way of diagnosing problems (soft and hard issues) in a specific project and improve future practice. However, as can be seen in the list of features of the FSM, it makes no specific reference to the subjective experience of people, i.e. 'super soft' factors such as passion and enthusiasm, creativity and innovation and culture and values which are particularly important within multidisciplinary design projects. This limitation is acknowledged by the authors themselves (Pearce and Fortune, 2002) and more research is under way to address this issue.

Table 4

Critical success factors from the study mapped onto component of the Formal Systems Model (Fortune et al., 2006)

\begin{tabular}{|c|c|}
\hline $\begin{array}{l}\text { Component of FSM } \\
\text { project attributes }\end{array}$ & Critical success factors from the study \\
\hline Goals and objectives & $\begin{array}{l}\text { Defined project goals } \\
\text { Shared project vision } \\
\text { Defined roles and responsibilities }\end{array}$ \\
\hline Performance monitoring & Project manage ment practices \\
\hline Decision-maker(s) & $\begin{array}{l}\text { Quality of leadership } \\
\text { Team selection and composition } \\
\text { Commercial awareness }\end{array}$ \\
\hline Transformations & $\begin{array}{l}\text { Techrical skills } \\
\text { Social skills } \\
\text { Team building process } \\
\text { Creativity and innovation } \\
\text { Effective inter-disciplinary team working } \\
\text { Time management }\end{array}$ \\
\hline Communication & $\begin{array}{l}\text { Rich communications } \\
\text { Knowledge sharing } \\
\text { Management of expectations } \\
\text { Feedback on progress }\end{array}$ \\
\hline Environment & $\begin{array}{l}\text { Organisational structure } \\
\text { Culture } \\
\text { Physical office environment }\end{array}$ \\
\hline Boundaries & Relationships \\
\hline Resources & $\begin{array}{l}\text { Sufficient resources } \\
\text { A ppropriate technologies }\end{array}$ \\
\hline \multirow[t]{2}{*}{ Continuity } & Client focus \\
\hline & $\begin{array}{l}\text { Mutual trust and understanding } \\
\text { Change management and flexibility } \\
\text { Motivation } \\
\text { Challenging task } \\
\text { Passion and enthusiasm } \\
\text { Shared values } \\
\text { Shared values } \\
\text { Recognition and appreciation }\end{array}$ \\
\hline
\end{tabular}


Figure 2.

The Formal Systems Model (from Fortune et al, 2006)

\section{Environment}

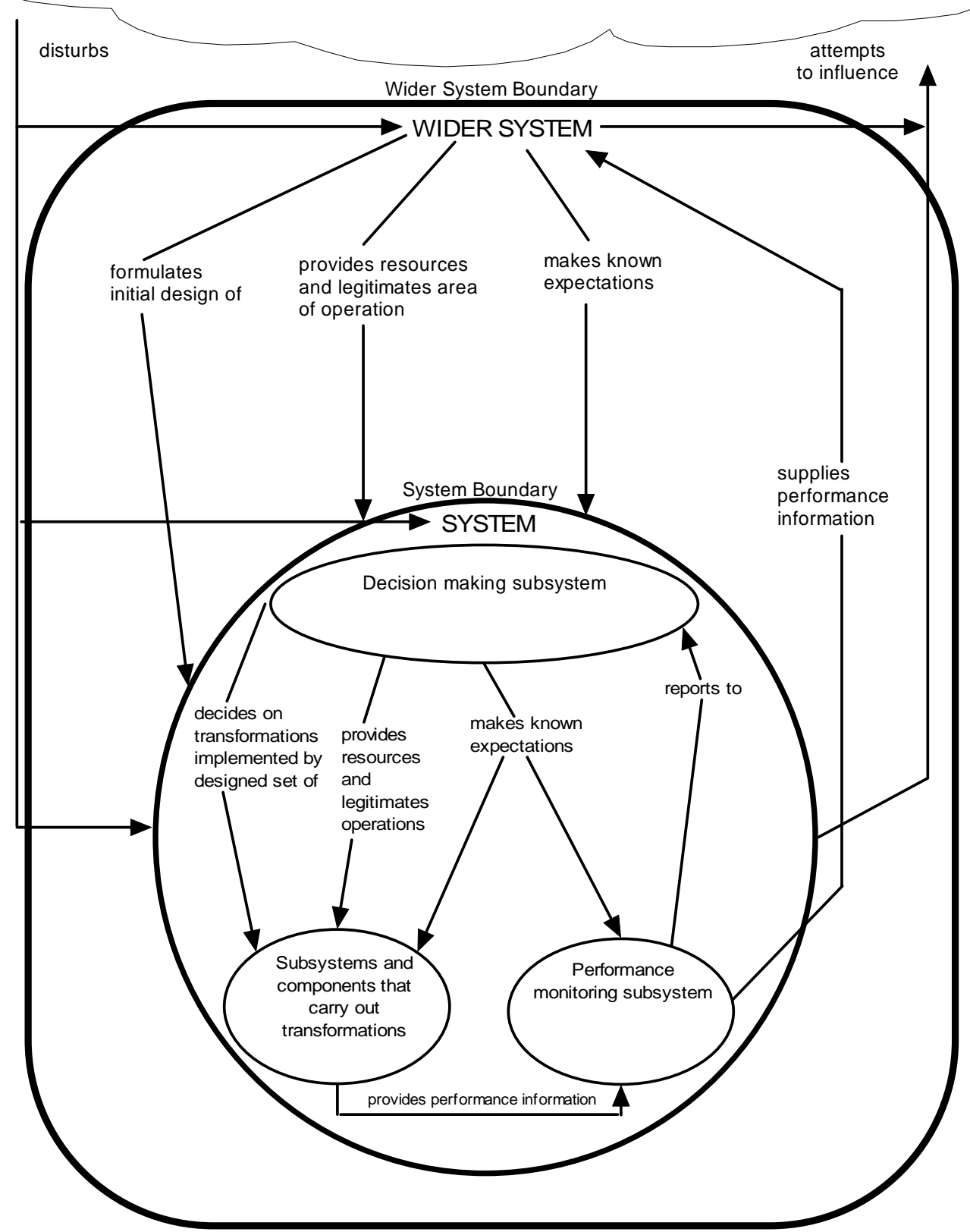




\section{DISCUSSION}

The research described in this paper aimed to elicit perceptions of CSFs related to delivery multidisciplinary design projects. More importantly, it goes beyond senior managements' conceptions of what 'has to go right' for success by including the perceptions of the team members themselves. There has been very little research into project success in such project settings, particularly in understanding the idiosyncratic context of design engineering and the multiple perspectives of 'success' that exist within the project community. This is surprising since design is such a critical part of the creation of the built environment.

The results of interviews, workshops and the survey with engineers and technicians revealed four interdependent success factor groups: management factors, design team factors, competency and resource factors and project enablers. These factor groups represent a subset of factors that are highly interrelated; issues in one group affecting issues in all of the others.

In light of the preceding results, although it is possible to explain each success factor in its own right, the interpretation of the interview material shows that in practice it is difficult to focus on a particular factor without acknowledging the influence of others. The sheer number of factors that were mentioned as critical and the apparent difficulty to prioritise confirm this. Interestingly, as participants began to reflect and talk about project success factors they started to add more factors to their 'list', allowing them to think more deeply about what the true drivers of success might be. This indicates that there is knowledge and wisdom about what makes projects successful, but the pressures of work, usually perceived as lack of time and resource, makes it difficult to take time out to reflect on success and CSFs.

In short, the four factor groups which were discerned in the data could be termed 'managerial challenges' because they represent socio-political, rather than technical challenges: managing the team in an evolving situation, clarifying goals and 'who is doing what' and managing staff changes and dynamics. Paradoxically, while there is widespread support and acknowledgment of the value of management and leadership, it seems that there is confusion as to what managers should be doing and how they can add value to inter-disciplinary design projects.

The picture shown indicates that since all projects exist within a specific organisational context, it is clear that the organisation (people) has to power to facilitate, influence and even impede project performance. In this respect, a basic overview of CSFs (see Table 3) can assist practitioners in the early project stages to make initial assessments regarding the multiple 'hard' and 'soft' factors that invariable affect the project implementation process. However, in the face of the inevitable complexities within the organisational environment, design teams themselves and the individuals who constitute those teams; there are no simple prescriptions for implementing effective project management practices.

Whilst in general the CSFs and factor groups presented appear to support those within the literature within construction and project management in general, the findings of this study reveal a number of 'new' factors which do not figure strongly in other success frameworks. These factors that are related to the socio-political dynamics of inter-disciplinary team work such as passion and enthusiasm, shared values, and creativity and innovation. In a sense this highlights a component of project success which can be termed 'personal success'. From the viewpoint of the project members themselves, feelings of positive emotion, joy, interest and contentment (see e.g. Fredrickson, 1998) is critical for perceptions of overall project success. It highlights the importance of personal success as an important component of project success. For example, it would appear that designers and CAD-technicians ability to work together and be productive in the project process depends partly on the perceived level of personal success. More specifically, performance is an outcome of perceived sense of challenge in their work, opportunities to develop creative and innovative solutions and being supported in that process. According to Amabile (1997) maintaining a positive emotion in the project environment depends on maintaining good team relationships, applying a suitable leadership style and matching people to work that utilises their skills and is clearly valued by management. The idea of positive emotions or sense of enjoyment is identical to the experience of flow or being in the zone. A 
growing body of studies in the field of positive psychology suggests that the benefits of actually 'doing what you love' is extremely important to individual and collective productivity and well being, and ultimately, organisational outcomes (Seligman, 2002; Csikszentmihalyi, 1990).

In other words, these variables are primarily related to human dimensions of work and thus act as enablers of project performance. Whilst practitioners are expected to deliver a successful project through people and relationships there often remains limited attention to the actual process of enabling individual and collective effort. As noted by Chinowsky et al (2001, p. 32) 'the traditional philosophy of management in architecture-engineering-construction (ACE) industry/.../places great emphasis on the ability to plan and execute projects'. This research suggest that multi-disciplinary project environments require emotionally intelligent or sensitive practitioners and project managers who can respond effectively to individual and team needs while at the same time ensuring that the project is delivered on time and within budget. Building design is a collaborative activity that requires cooperative behaviours and interpersonal skills, but the engineers value their independence and being self-managed (Lowendahl, 2005). This is understood to demonstrate two important dimensions for the management of socially complex projects: 1) the importance for both technical as well as soft skills and the propensity to evaluate technical input and performance as well as propensity to cooperate; and 2) the relevance of understanding the classic tension between the individual and the organisation and 'the wish to join together and the wish to be separate' dilemma (Stokes, 1994).

Due to time pressures in the multi-project environment too much of project management is focused only on meeting deadlines or submitting stage reports and fails to address the day to day nuances that are so important in practice. These include the needs of the people within the team, supporting the collaborative process and listening and providing feedback on progress. This situation is an example of what Frankenberger et al (1997) refers to as the economic pressure of engineering design practices where by engineering designers are struggling not so much with technical problems, but rather with difficulties related to their surroundings (e.g. effective organisation, management, communication) and colleagues. When given time to reflect on project work, practitioners become aware of the wider context in which they conduct their work. For instance, many of the perceived barriers to success relate to frustrations with the nature of construction industry. It is felt to be 'fragmented, risk averse and overly contractual'. The way in which projects are set up and run does not necessarily support team integration, communication flow and coordination of design information. Thus, the success of multi-disciplinary projects cannot be attributed solely to the team and the team members' competencies.

Consequently, success in a multidisciplinary practice depends on active and continuous management of process and people as well as an ability to improvise through frequent communication and reflection. Indeed, rich communications was singled out as the factor which underpins the performance of all success factors. According to Bales (1950) effective team communication focuses on what he termed both 'task' and 'maintenance behaviours'. Task behaviours are focusing on accomplishing the task at hand. These include such behaviours as asking or sharing information, and checking for comprehension. Maintenance behaviours focus on developing and preserving cooperative relationships among group members. Such behaviours include supporting and praising others and encouraging participation. In a multi-project organisation such as engineering consultancy, the communication culture is often such that information often gets lost in the process of 'getting the work done', increasing the likelihood of mistakes, repeat work and failing to meet the client's expectations. Therefore, ensuring that the right people are talking together is vital, which means that communication is not about passing paper from one point to another; it is about bringing the right information to the right person. The constraint lies in the nature of design project work; the involvement of architects and other subcontractor that represent organisations that operate outside of the engineering consultancy. They are typically viewed as communication based (Winch, 2001); efficient collaboration relies on effective diffusion of information throughout the project (Baiden, et al., 2006).

This suggests that it is important to take a broader view of the factors that are considered to influence effectiveness, in particular, acknowledging the importance of extremely intangible 
factors such as creativity and emotional feelings which are often overlooked by practitioners. These factors are typically seen as important by everyone but are difficult to measure.

Taken together, the findings suggest project participants in inter-disciplinary projects view successful projects as largely deriving from project team and management characteristics; having very clear project goals, clear roles and responsibilities, an appropriate mix of skills people in the team, supportive management and effective, open communication throughout the project life cycle. Additionally, what is also seen as 'critical' is the project members' 'affinity' to the project itself (see Dainty et al., 2005), which shows that intrinsic motivation is an important aspect for understanding engineers and technicians' creativity and performance in project work. This was referred to as 'passion' for the project.

While the pressure to deliver on time and on budget are still dominant within the interdisciplinary project organisation, team members themselves are also interested in whether a project is worthwhile doing, satisfying and is a good learning experience (i.e. they are focused on psycho-social outcomes).

Overall, perhaps the most significant finding is that the identification of CSFs only provides partial insights on how to improve the performance of projects. This is a reminder that projects are thoroughly social endeavours. This supports the notion that success is socially constructed among the project members, which has been found in studies of project managers in an R\&D lab (Smith-Doerr et al, 2003). The message is that the management of inter-disciplinary projects requires an approach where the best way to manage all projects (including CSFs) is to 'identify the contingencies that matter and what to do about them' (Morris et al., 1987, p. 29). From a managerial perspective it is therefore relevant to identify CSFs that makes sense for the team rather than identifying one 'right' list.

\section{CONCLUSIONS AND PRACTICAL IMPLICATIONS}

Managers within the ACE industry consistently face the question of how to encourage high technical performance and greater collaboration among engineers and technologists. An added layer of complexity is that the everyday realities of managing design consist of being able to tackle 'the evolving nature of the situation' and the need to continually deal with emerging issues. The research indicates that while project success still depends on formal project management methods (planning and control of resources and costs), and availability of skilled people, the key point is that team members need to work with each other in a supportive context to achieve successful project outcomes. This is particularly pertinent for interdisciplinary projects such as building design which are characterised by their dynamism, iterative nature and non-linearity. Thus, facilitating project success within an inter-disciplinary design context necessitates a balancing of various factors relating to tensions and dynamics between individuals and within teams. The most interesting finding in the study is that factors peculiar to achieving successful project outcomes in collaborative design projects are closely related to the sociopolitical dynamics of inter-disciplinary team work such as passion and enthusiasm, shared values, creativity and innovation. These so-called super-soft factors are especially important in stimulating personal success which seems to be inextricably linked to perceptions of project success. The implication is that project participant's sense of creative performance and affinity to the project as well as the team itself has to be taken seriously as levers to achieve positive project outcomes. Since engineering design is based on the creative energy of the engineers (and architects) this is perceived as a critical process in achieving a successful project. It highlights that multi-disciplinary project environments require leaders who are socially competent and engage in building teams, drawing attention to the socio-political factors as important enablers for success. From this perspective, it may be timely for managers and practitioners in construction to consider the emotional aspects of interdisciplinary teamwork and reflect on how this may enhance positive project outcomes.

Overall, the results of the study have a relatively simple but important implication: managers who wish to achieve inter-disciplinary project success must pay careful attention to their own everyday practices and behaviour within the project context. In other words, by 
recognising that they have the power to influence, motivate and enhance positive feelings and creative performance the 'right' success model can be developed over time through continuous learning and reflection. Thus if CSFs are seen as an integral part of managing projects, it may have a more profound effect on people, practice and performance. Long term this implies developing individuals with an engineering background to take on a more comprehensive management role one which includes the management of multi-disciplinary teams, requires investment and further research. However, the concept of multi-disciplinary team leadership remains a relatively new one. Crucially, it may be that inter-disciplinary team leadership may be a critical role for construction professionals.

Ultimately the study shows that simply attempting to identify and classify CSFs is not enough in understanding how project success can be achieved in complex projects. While the authors acknowledge this limitation in the study the work provides an insight into the peculiar context of inter-disciplinary design projects and thus adds to the existing literature on CSFs and project success in construction related organisations and beyond. It supports the growing trend to use systems thinking in the management of projects. The promise of applying systems thinking lies in developing a (mental) model which may enable practitioners and managers to become more attuned to the inherent interdependencies of the contextual factors which influence positive project outcomes including their own potential to influence everyday practices. But for it to be useful for practitioners, this holistic framework of CSFs must also incorporate a theory which explains behaviour beyond a simple description of what people are doing when they work together in projects. Work is under way to carry out a real time study of a group of interdisciplinary projects with the view to gaining a more comprehensive understanding of the actuality of complex projects and their implications for management practice and project success. The aim is to develop the Formal Systems Model (FSM) so that it incorporates the 'super soft' factors which are important in fluid and agile project environments. In order to accomplish this goal a grounded theory approach will be used to conceptualise behaviours in the project environments by looking into what happens when project participants collaborate to produce inter-disciplinary projects. Knowledge and understanding of social processes at work may enable managers to understand their functionality in resolving project participant's concerns and needs in response to persistent and unpredictable change in complex projects. In particular it offers valuable insights on several issues of specific significance to management praxis in collaborative practices including communication, learning and innovation, engagement and satisfaction at work.

Acknowledgements: The authors wish to thank the project's industrial collaborators for their continuous assistance and support. 


\section{REFERENCES}

Allinson, K. (1997), Getting there by design: An architect's guide to design and project management, Architectural Press, Oxford.

Andersen, E. S., Birchall, D., Jessen, S.A., and Money, A. H. (2006), Exploring critical success factors, Baltic Journal of Management, Vol. No 2, pp. 127-147

Boyatzis, R. (1998,). Transforming qualitative information: Thematic analysis and code development Sage, Thousand Oaks.

Bresenen, M. (1990), Organising construction: Project Organisation and matrix Management, Routledge, London.

Bresnen, M., Goussevskaia, A. and Swan, J (2005) Managing projects as complex social settings, Building, Research and Information. 33(6), 487-493.

Busseri, A. and Palmer (2000) Improving teamwork: the effect of self-assessment on construction design teams, Design Studies, Vol 2, pp. 223-238.

Cicmil, S. (2005), Reflection, participation and learning in project environments: a multiple perspective. In: P. Love, P. S. W. Fong, and Z. Irani (Eds.) Management of Knowledge in project environments, Oxford, Elsevier Butterworth Heinemann.

Cooke-Davies, T. (2002), 'The 'real' success factors on projects', International Journal of Project management, 20, pp.185-190.

Cooke-Davies, T. (2004), Project Success, in Pinto, J.K and Morris, W.G., (Eds.), The Wiley Guide to project management, Wiley \& Sons Inc, Hoboken, New Jersey.

Csikszentmihalyi, M. (1990), Flow: The Psychology of Optimal Experience. Harper and Row, New York.

Baker, B. N. Murphy, D. C. and Fisher D. (1988), 'Factors affecting project success'. In D.I Cleland, W.R King, (Eds.), Project Management Handbook, Van Nostrand Reinhold, pp. 902-919.

Chan, P.C., Scott, D., and Chan, P.L (2004) Factors affecting the success of a construction project, Journal of Construction Engineering and Management, Jan/Feb, pp. 153-155.

Chan A.P.C. and Chan A.P.L. (2004) Key performance indicators for measuring construction success, Benchmarking: An International Journal, Vol 11, No 2, pp. 203-221

Détienne, F. (2006) Collaborative design: Managing task interdependencies and multiple perspectives, Interacting with Computers, Vol 18 Vol 1, pp. 1-20.

Dainty, A. R., Alan Bryman, A., Price, A. D. F., Greasley, K., Soetanto, R, and King, N. (2005), 'Project affinity: the role of emotional attachment in construction projects', Construction Management and Economics, Vol http://www.informaworld.com/smpp/title $\sim$ content=t713664979 db=all $\sim \mathrm{tab}=$ issueslist $\sim$ branches $=23$ - v2323 No 3, pp. 241-244.

De Long, D.W. and Fahey, L. (2000), 'Diagnosing cultural barriers to knowledge management', Academy of Management Executive, Vol. 14 No 4, pp.113-27.

Dougherty, D. (1992), 'Interpretative barriers to successful product innovation in large firms'. Organization Science, Vol 3 No 2, 179-202.

Egan Report: Sir John (1998), Rethinking Construction: The Report of the Construction Task Force to the Deputy Prime Minister on the Scope for Improving the Quality and Efficiency of UK Construction. The Stationary Office, London.

Fong, P. (2005), 'Co-creation of knowledge by multidisciplinary project teams'. In: P. Love, P.S.W., Fong and Z, Irani (eds.) Management of knowledge in project environments. Oxford: Elsevier Butterworth Heinemann

Fredrickson, B. (1998), What good are positive emotion?, Review of general psychology, Vol. 2, No 3, pp. 300-319.

Fortune, J. and White, D. (2006), 'Framing of project critical success factors by a systems model', International Journal of Project Management, Vol 24, No 1, pp. 53-65. 
Frankenberger, E. and Auer, P. (1997), 'Standardized observation of team-work in design', Research in Engineering Design, Vol. 9, pp. 1-9

Jugdev, K and Müller, R. (2005), 'A retrospective look at our evolving understanding of project success’, Project Management Journal, Vol 36 No 4, pp. 19-31.

Kunda, G. (1992), Engineering culture. Control and commitment in a High-Tech corporation, Temple University Press, Philadelphia.

Koch, C. (2004), 'The tyranny of projects: team working, knowledge production and management in consulting engineering'. Economic and Industrial Democracy, Vol 25 No 2, pp. 277-300.

Koch, C. and Bendixen, M. (2005), 'Multiple perspectives on organizing, projects between tyranny and perforation', Building research \& Information, Vol 33 No 6, pp 536-546.

Latham Report: Sir Michael Latham (1994), Constructing the Team: The final report of the government/industry review of procurement and contractual arrangements in the UK construction industry. HMSO, London.

Lowendahl, B. R. (2005), Strategic Management of Professional Service Firms, Copenhagen Business School Press.

Meredith, J. R. and Mantel, S. (2006), Project management: A managerialist approach, $6^{\text {th }}$ ed,. Wiley: New York.

Morris, P. (2006), Afterword: making the management of projects critical, in Hodgson, D and Cicmil, C (Eds.), Making projects critical, Palgrave Macmillan, Hampshire, pp. 335-347.

Nandhakumar, J. (1996), Design for Success?: Critical Success Factors in Executive Information Systems Development, European Journal of Information Systems, Vol 5, No 1, pp. 62-72.

Newell, S., Robertson., Scarrough, H. and Swan, J. (2002), Managing knowledge work, Palgrave Macmillan, Hampshire.

Obholzer, A. and Roberts, V.V (1994), The unconscious at work: individual and organisational stress in the human services, Routledge: London.

Pinto, J.K. and Morris, W.G. (2004), The Wiley Guide to managing projects, John Wiley \& Sons Inc., Hoboken, New Jersey.

Pryke, S. and Smyth, H. (2006), The management of complex projects: A Relationship approach, Blackwell Publishing, Oxford.

Rockart, J. F. (1979), Chief Executives define their own data needs, Harvard Business Review, Vol 57 No 2, 81-93.

Seligman, M.E.P (2002) Authentic happiness. Free Press: New York.

Shenhar, A. J. Dvir, D., Levy, O. and Maltz, C. (2001), 'Project success: A multidimensional strategic concept’, Long Range Planning, Vol 34, No 6, pp. 699-725.

Stapley, L. F. (2006), Individuals, groups and organisations beneath the surface: An introduction, Karnac Books, London.

Stokes, J. (1994), 'The unconscious at work in groups and teams', in Obholzer, A. and Roberts, V. Z (Eds.), The Unconscious at Work: Individual and Organizational Stress in the Human Services, Routledge, London, pp. 19-27.

Thomas, J. (2006),. 'Problematising project management', in Hodgson, D and Cicmil, S, Making projects critical, Palgrave MacMillan, London.

Winch, G. M. (2002), Managing construction projects: An information processing approach, Publishing, Oxford.

Yin, R (1993), Applications of case study research. Sage Publishing, Newbury Park, CA:

Zwikael, O. and Globerson, S. (2006), 'From critical success factors to critical success processes. International Journal of Production Research, Vol 44 No17, 3433 - 3449. 